\title{
ENVIRONMENTAL INFLUENCES ON GRAVIMETRIC EARTH TIDES OBSERVATIONS
}

\author{
J. Bogusz \\ Warsaw University of Technology \\ e-mail: jb@gik.pw.edu.pl
}

\begin{abstract}
The following article presents the results of the adjustment (by means of the classical least squares method) of 3-year series of gravimetric Earth tides observations recorded in Observatory at Jozefoslaw (Józefosław - Poland) using LaCoste\&Romberg model ET-26 gravimeter. The set of atmospheric data (pressure, temperature and humidity) has been taken into account in the analysis. Several models of ocean's tides were compared to find out how large the indirect effect in Jozefoslaw is. Hydrological observations were made parallel to the gravity storage (soil moisture, water table changes, and rainfalls) to specify its influence to the gravity. Joint adjustment allowed us to determine reliable and precise model of gravimetric Earth tides for Jozefoslaw, which is an indispensable element for every geodynamical observatory. From 3-year data series we were able to obtain parameters (amplitude factor and phase shift) for 31 tidal components. The accuracy of single observation after adjustment $\left(4.2 \mathrm{~nm} / \mathrm{s}^{\wedge} 2\right)$ and the drift $\left(-4.5 \mathrm{~nm} / \mathrm{s}^{\wedge} 2\right.$ per month) are acceptable for this type of equipment. It is worth indicating that these observations are one of the most accurate that have ever been carried out in Poland.
\end{abstract}

Keywords: Earth Tides, gravimetry.

\section{INTRODUCTION}

The Astrogeodetic Observatory in Jozefoslaw is located in the central Poland $\left(B=52^{\circ} 05^{\prime}\right.$ $50.2^{\prime \prime} \mathrm{N}, \mathrm{L}=21^{\circ} 01^{\prime} 53.5^{\prime \prime} \mathrm{E}, \mathrm{H}=141 \mathrm{~m}$ ) very close to Warsaw. It lies at East European Craton, as presented in figure 1 .

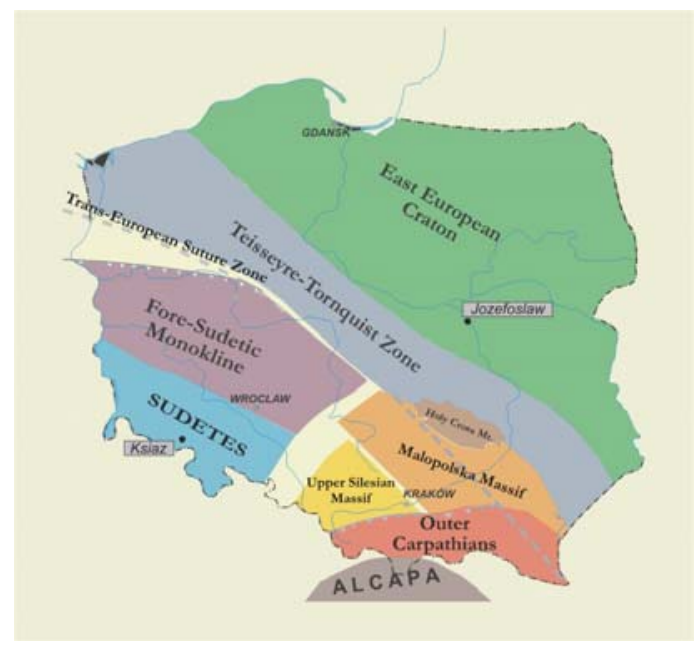

Fig. 1. Observatory at Jozefoslaw 
Tidal gravimetric observations in the Observatory started in 1993 using LaCoste\&Romberg model G gravimeter. Since 2001 the Observatory has been equipped with the ET-26 model dedicated to the stationary gravimetric measurements. The tidal research program also encompasses environmental studies to make the results more genuine. This study presents the analyses of the data which has been collected from 2002 to 2005 .

\section{EQUIPMENT AND DATA ACQUISITION}

The ET-26 gravimeter is situated in the Astrogeodetic Observatory in Jozefoslaw on the pillar located $5.5 \mathrm{~m}$ deep to reduce microseisms, into a thermally stabilized chamber. The temperature in the room is stable up to $0.2^{\circ} \mathrm{C}$. Computer's clock is synchronized once every 1 hour using internet and time signal from Borowiec Astrogeodynamic Observatory (vega.cbk.poznan.pl). The stability of the pillar is monitored by the electronic levels built-in the gravimeter, but the instrument has no automatic tilt compensation.

This research concerns the observations collected from 2002 to 2005 (fig. 2). The data is stored on the computer with 1 minute sampling interval using software provided by LaCoste\&Romberg. Spikes, gaps and steps were removed using TSoft software (Van Camp and Vauterin, 2005), downloaded from International Centre for Earth Tides web page http://www.orb.be/ICET/home.html.

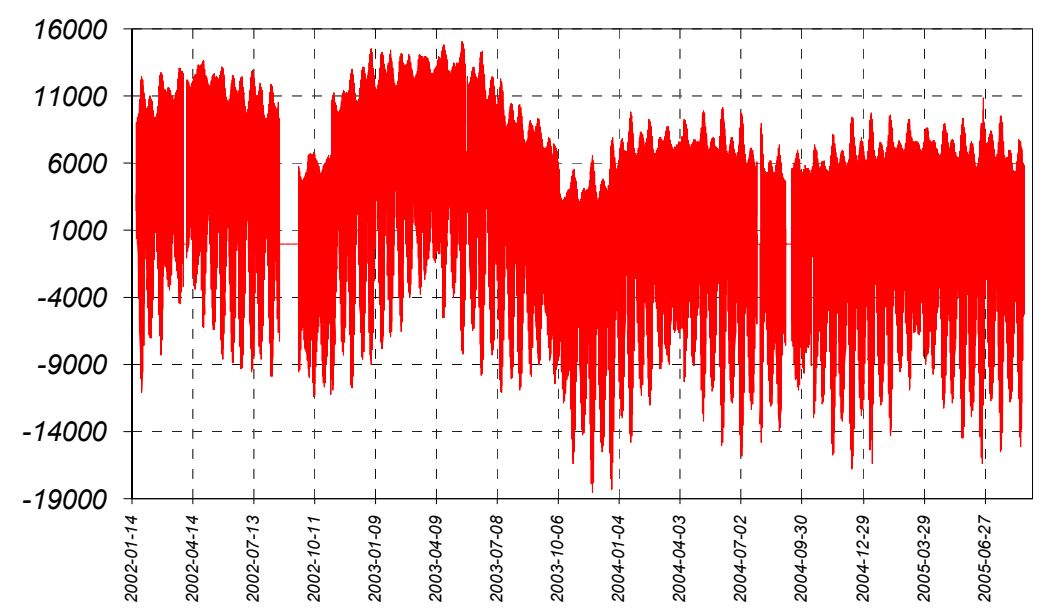

Fig. 2. Gravity observations collected from 2002 to 2005 [nm/s^2]

The difference between gravity observations and theoretical values derived from the tidal development for ET-26 is presented in fig. 3.

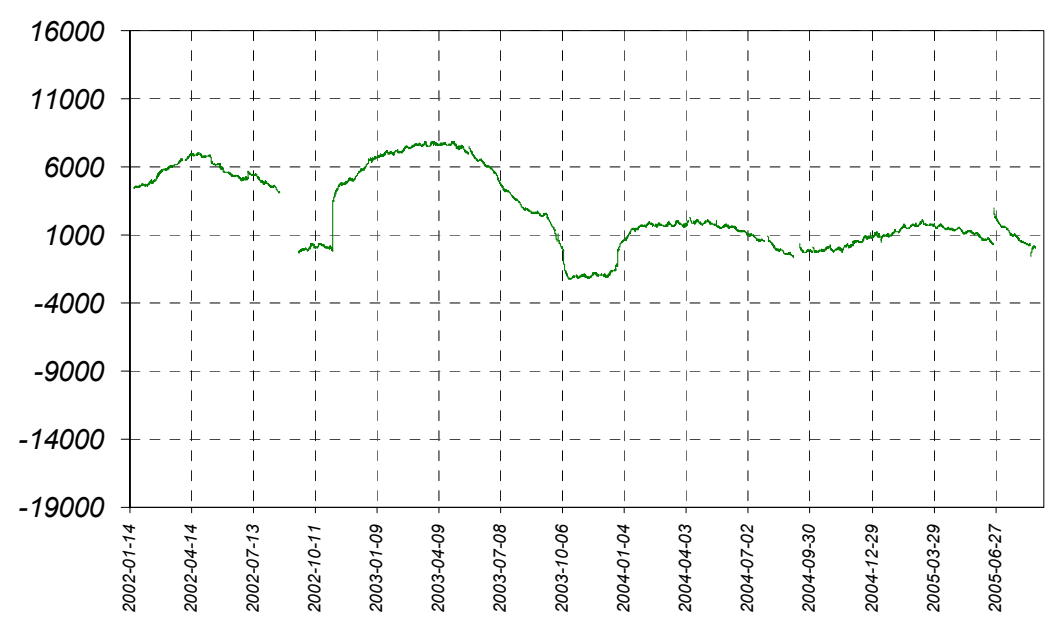

Fig. 3. Difference between observations and theoretical tides $\left[\mathrm{nm} / \mathrm{s}^{\wedge} 2\right]$ 


\section{ENVIRONMENTAL EFFECTS}

In gravimetric tidal observations particularly special attention is paid to environmental effects. These effects affect gravity in the tidal frequencies and hence are not possible to be removed using statistical methods (Melchior, 1983). The main of them are:

1. ocean loading;

2. atmospheric mass variations;

3. hydrological influences (ground water table, rainfalls, soil moisture, etc.).

\subsection{Observational programme}

The observational programme of the environmental effects encompasses four kinds of observations:

1. ambient pressure, temperature and humidity;

2. ground water level;

3. soil moisture;

4. rainfalls.

In figure 4 particular sensor's locations are presented.

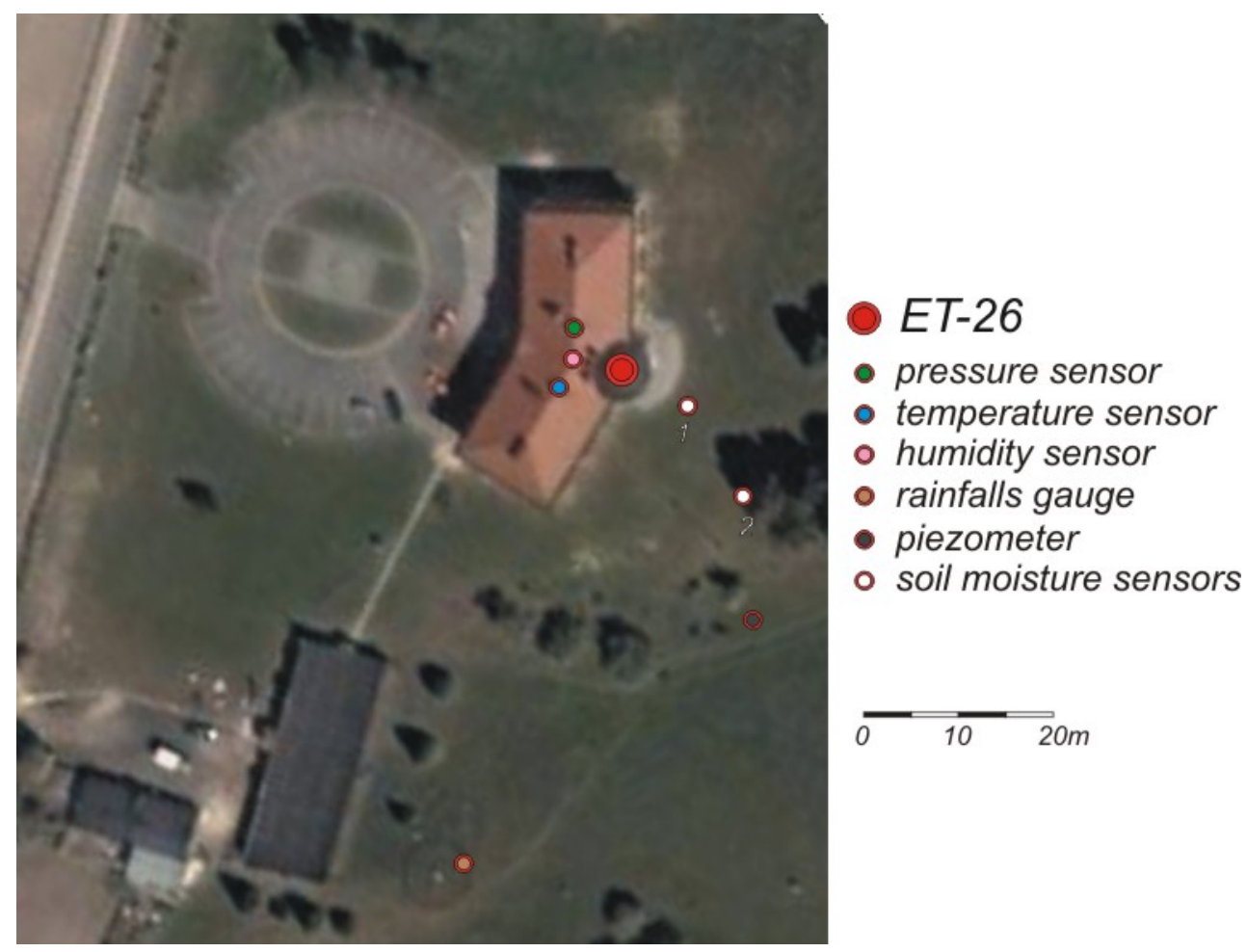

Fig. 4. Location of the sensors.

\subsection{Ocean loading}

This effect is caused by the ocean's tides and its "indirect" influence to the Earth's tides. The distribution of the oceanic waters varying with the tides is represented by the cotidal charts. This denomination is given to special maps of the ocean bearing a superposition of equalheight lines (co-amplitudes lines) and equal phase lines (cotidal lines) describing for every tidal constituent the periodic movement of the oceanic water under the influence of the tidal potential and the Coriolis force due to the rotation of the Earth (Melchior, 1983). 
Calculation of the ocean indirect effect depends on the convolution sum between ocean tides distribution in particular frequencies and gravity Green's functions calculated for considered Earth's model (PREM in this study). Special service of ocean loading effect was established. It is available on web page http://www.oso.chalmers.se/ loading/.

Several models for Jozefoslaw Observatory were tested. They were: FES95, FES02, CSR3, CSR4, ORI96 and GOT00. These test gave very similar results (maximum difference of $0.3 \mathrm{~nm} / \mathrm{s}^{\wedge} 2$ for M2 wave) as far as this effect at the Observatory is very weak when we compare it to the coastal sites. Figures 5 to 7 present amplitudes, phases and total ocean indirect effect respectively, calculated using GOT00 model (Ray, 1999).

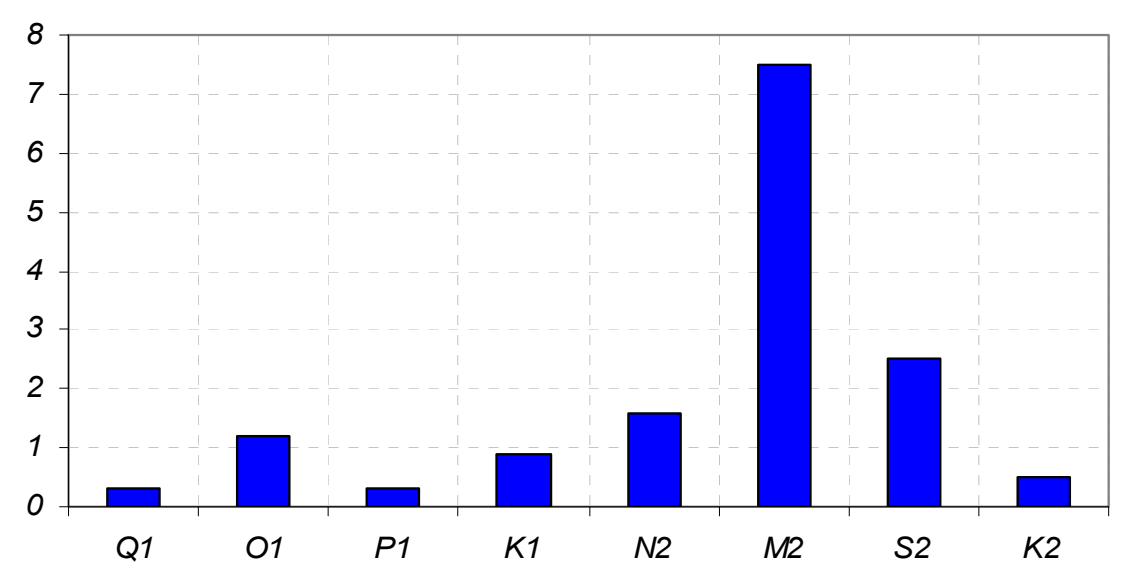

Fig. 5. Amplitudes $\left[\mathrm{nm} / \mathrm{s}^{\wedge} 2\right]$ of ocean indirect effect.

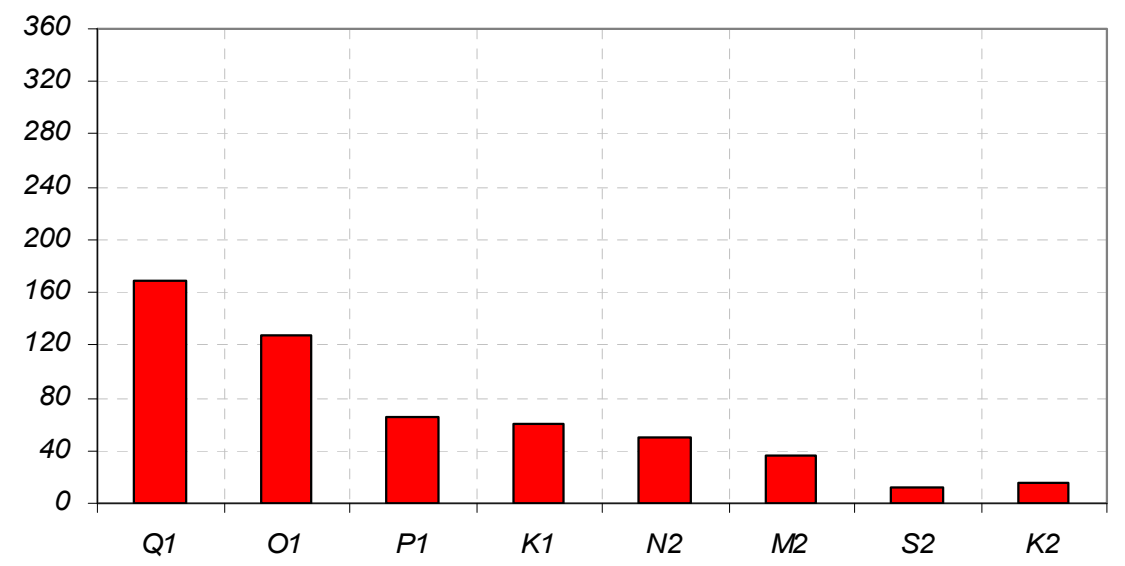

Fig. 6. Local phase $\left[^{\circ}\right]$ of ocean indirect effect. 


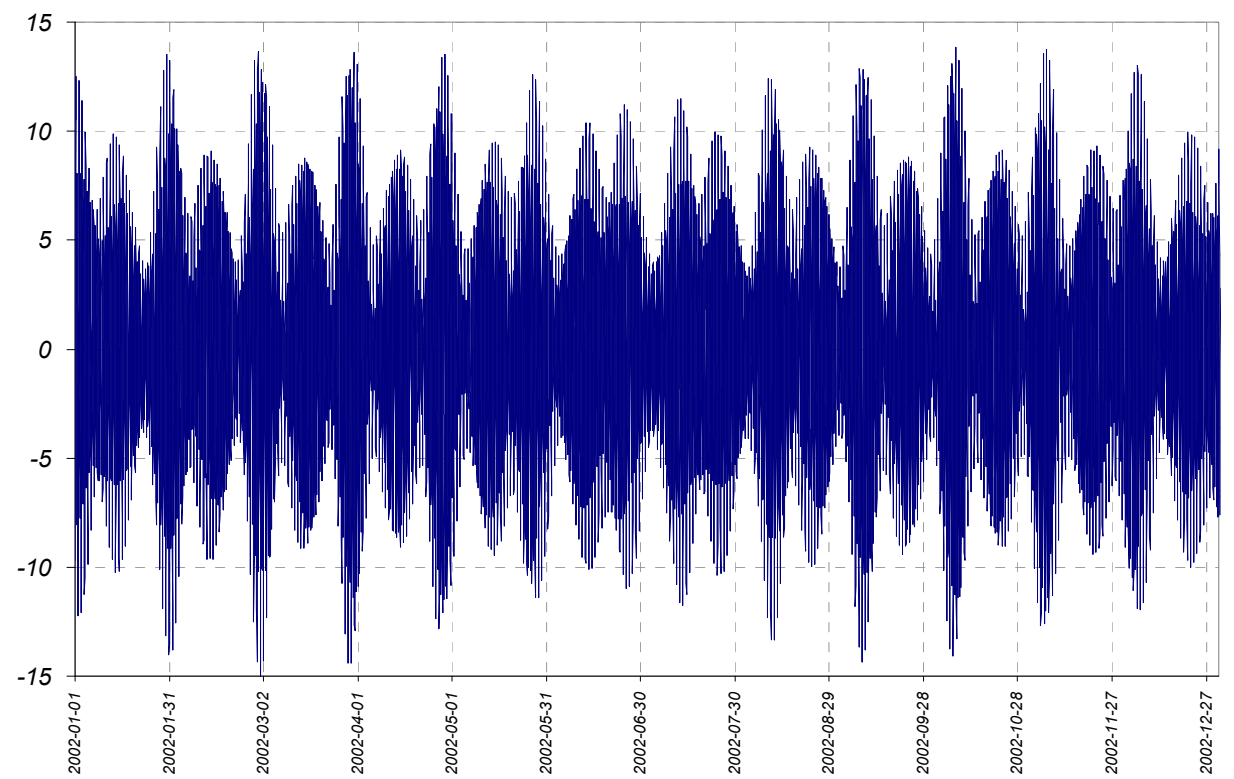

Fig. 7. Ocean indirect effect $\left[\mathrm{nm} / \mathrm{s}^{\wedge} 2\right]$ for Jozefoslaw Observatory.

\subsection{Atmospheric mass variations}

This effect is very similar to the oceanic influence, but it is caused either by the redistribution of atmospheric masses.

In this research only data for the observatory was used. Three atmospheric observations have been made at Jozefoslaw: pressure, temperature and humidity, presented in figures 8, 9 and 10 respectively.

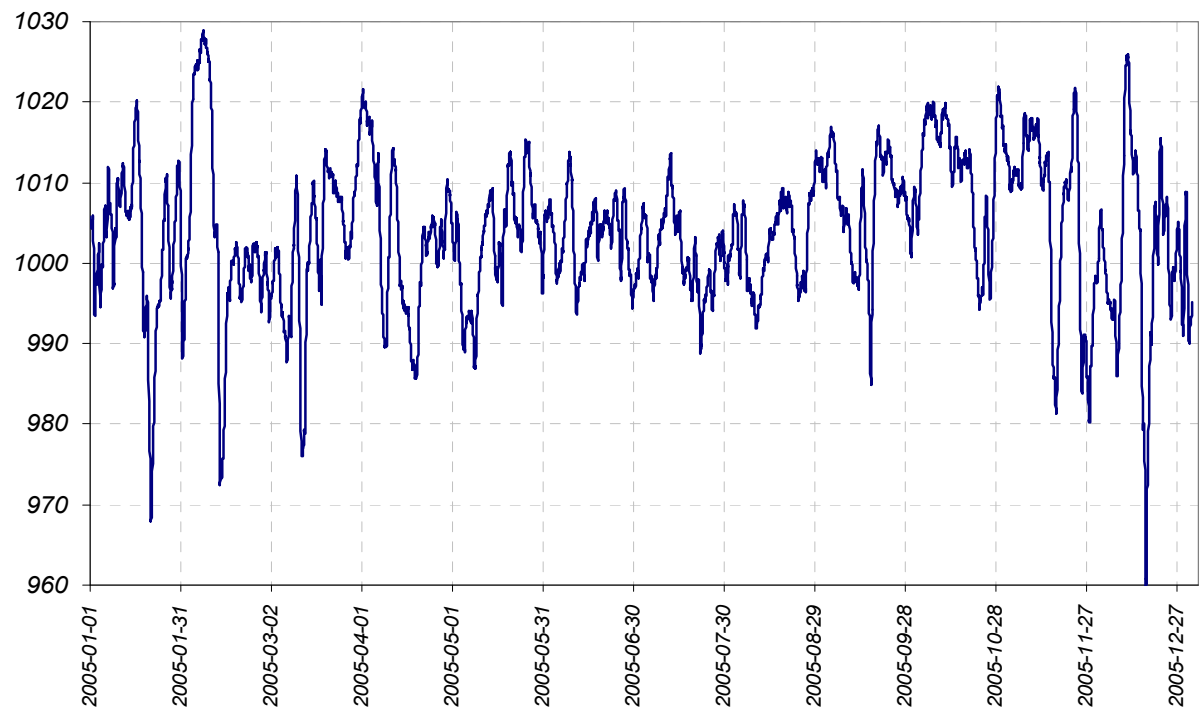

Fig. 8. Air pressure changes $[\mathrm{hPa}]$ in 2005 . 


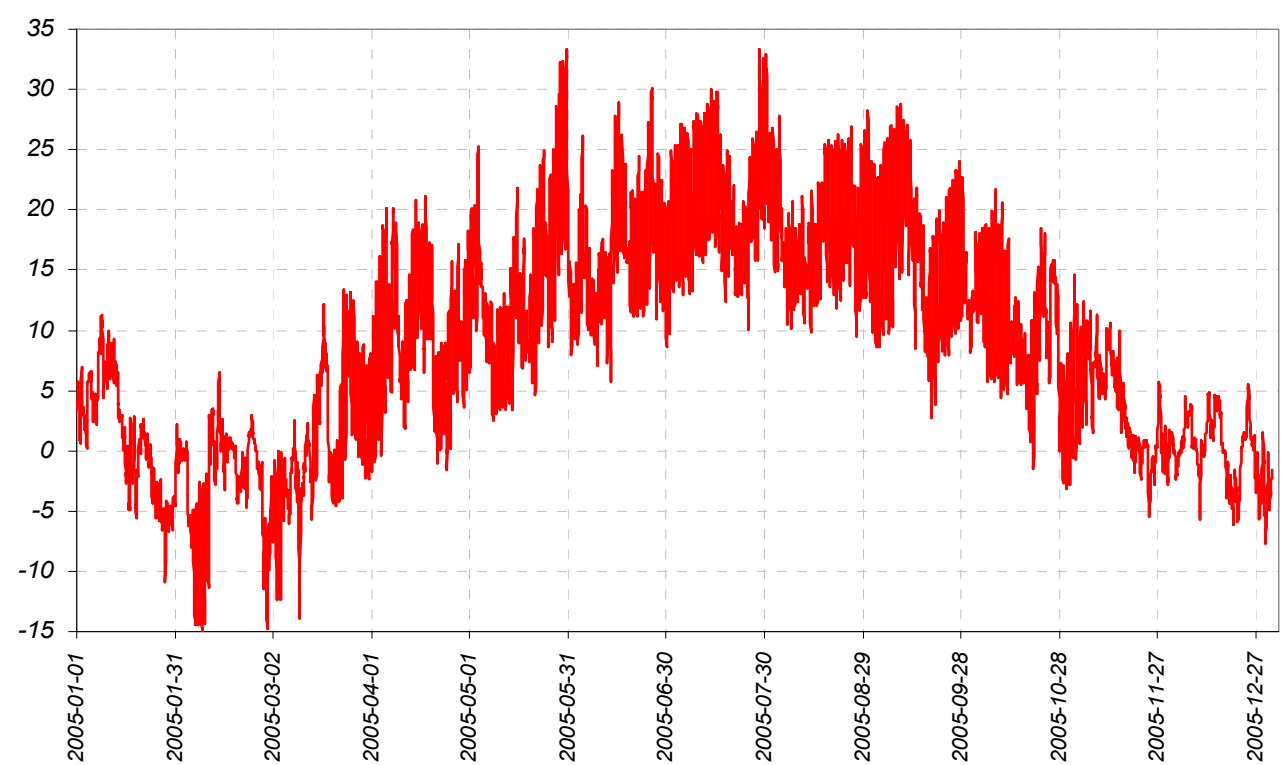

Fig. 9. Air temperature changes $\left[{ }^{\circ} \mathrm{C}\right]$ in 2005

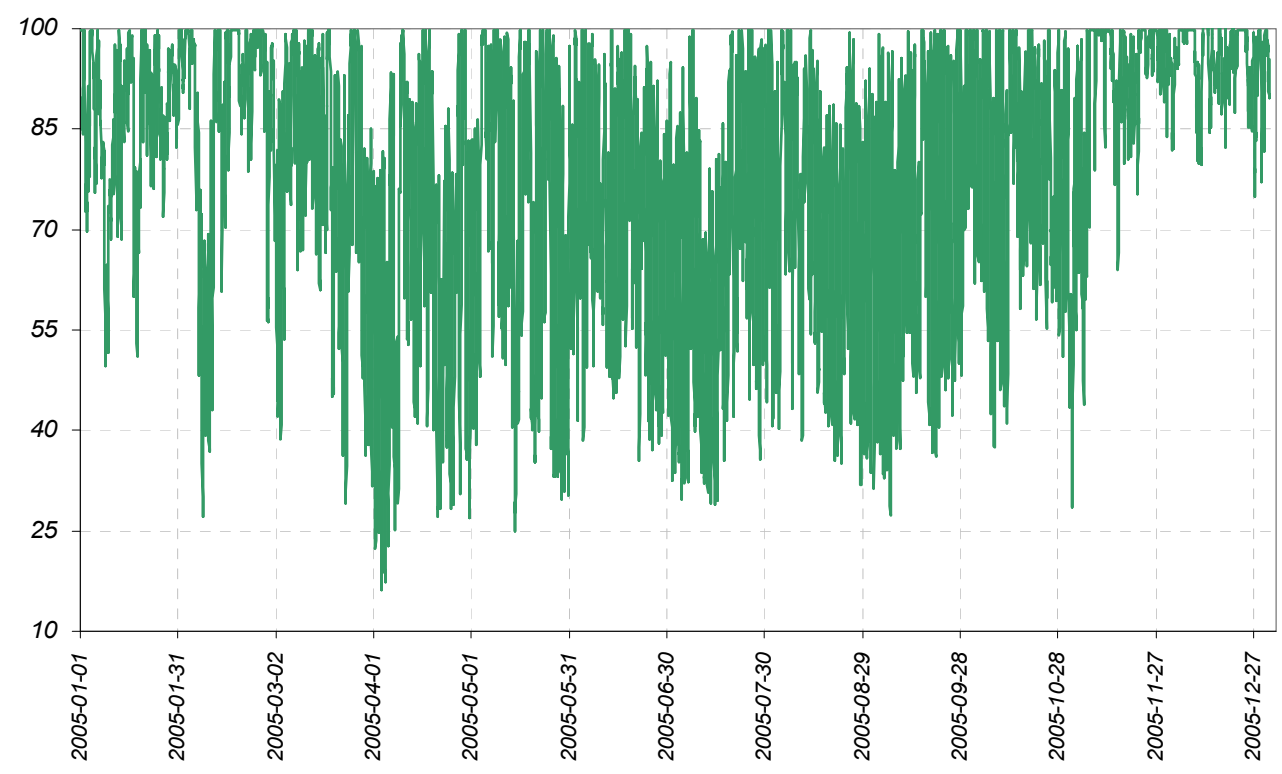

Fig. 10. Air humidity changes [\%] in 2005.

Gravitational changes due to the atmosphere (fig. 11) were calculated using single regression coefficient which was determined for Jozefoslaw Observatory according to regional meteorological data, Green's functions and procedure widely described in (Farrel, 1972). Then single regression coefficient between these changes and the tidal residuals was calculated. This coefficient is (Bogusz, 2000):

$$
\Delta g\left[\mathrm{~nm} / \mathrm{s}^{2}\right]=-3.45 \cdot \Delta p[\mathrm{hPa}]
$$




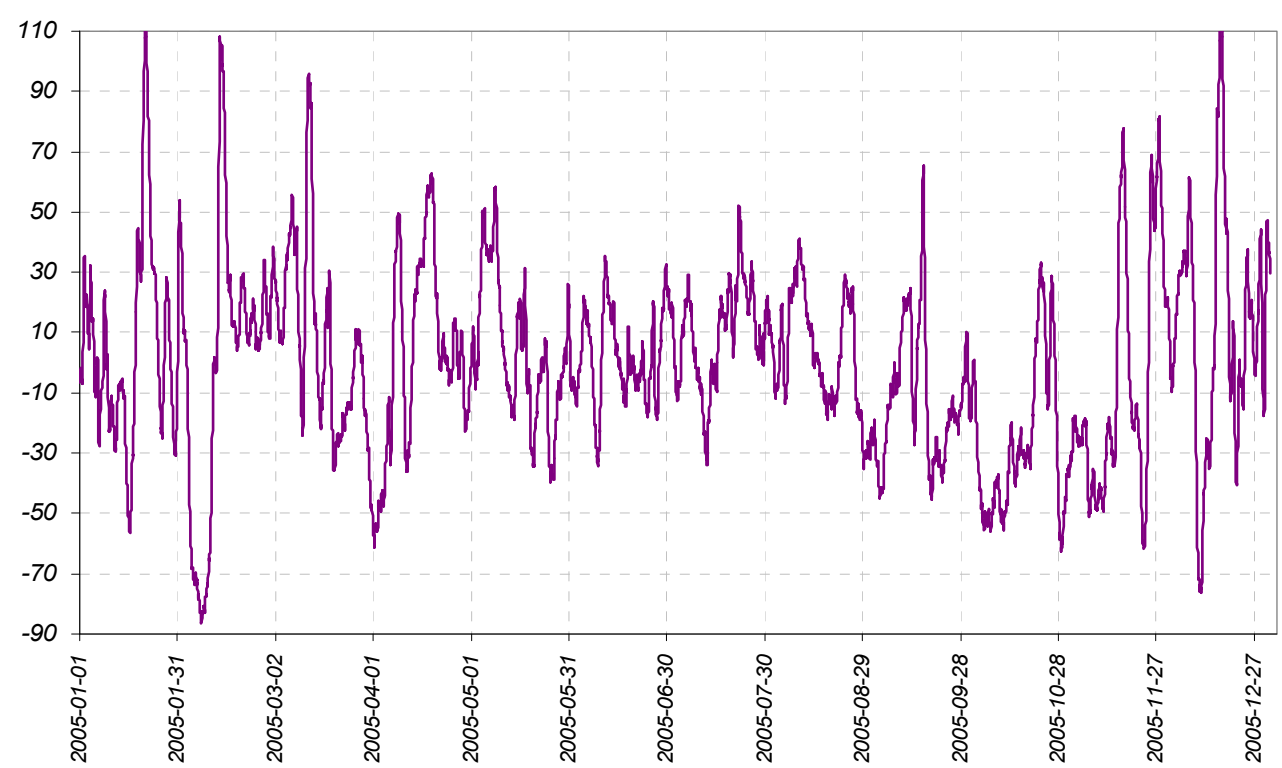

Fig. 11. Atmospheric gravity effect $\left[\mathrm{nm} / \mathrm{s}^{\wedge} 2\right]$ in Jozefoslaw.

To determine tidal changes atmospheric effect was analyzed using Eterna 3.4 package (Wenzel, 1996). Figures 12 and 13 present amplitudes and phases of the atmospheric gravity effect. Error bars come from Eterna package calculation. The main role play S1 and S2 solar waves, because in case of the atmosphere thermal excitation is dominant to the gravitational one.

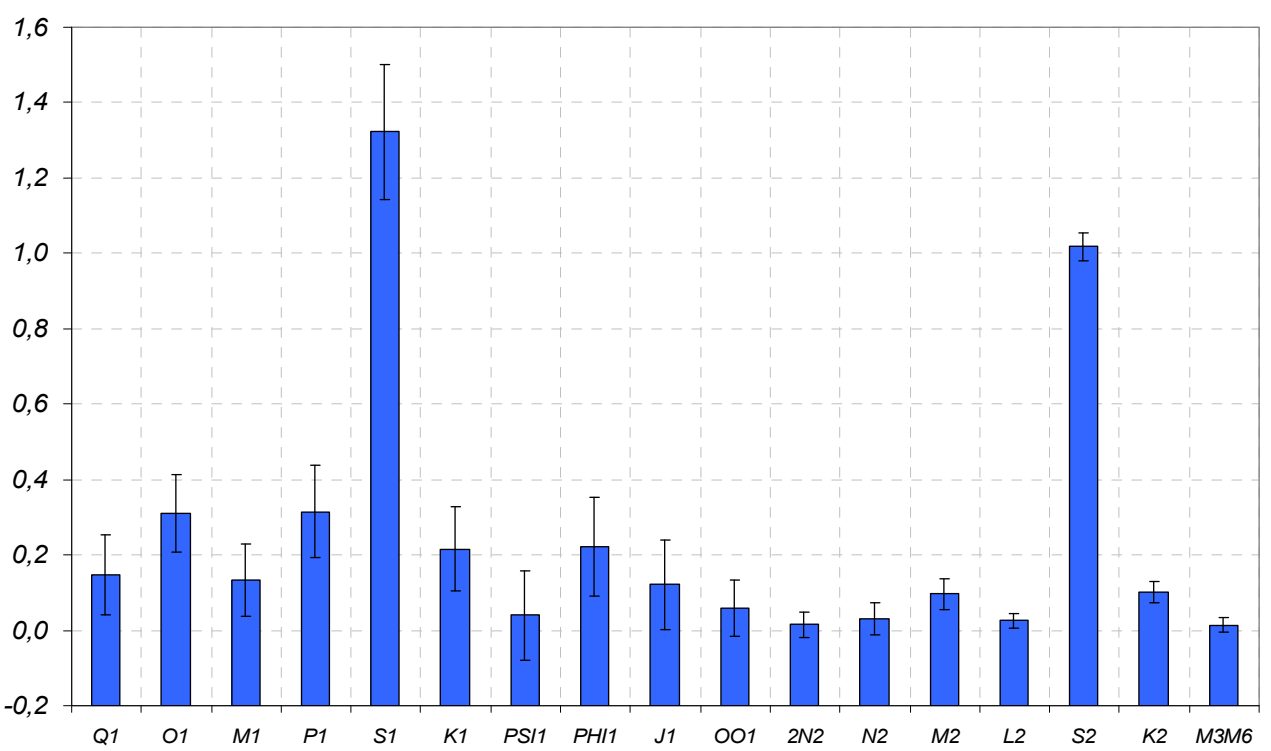

Fig. 12. Amplitudes $\left[\mathrm{nm} / \mathrm{s}^{\wedge} 2\right]$ of the atmospheric gravity effect. 


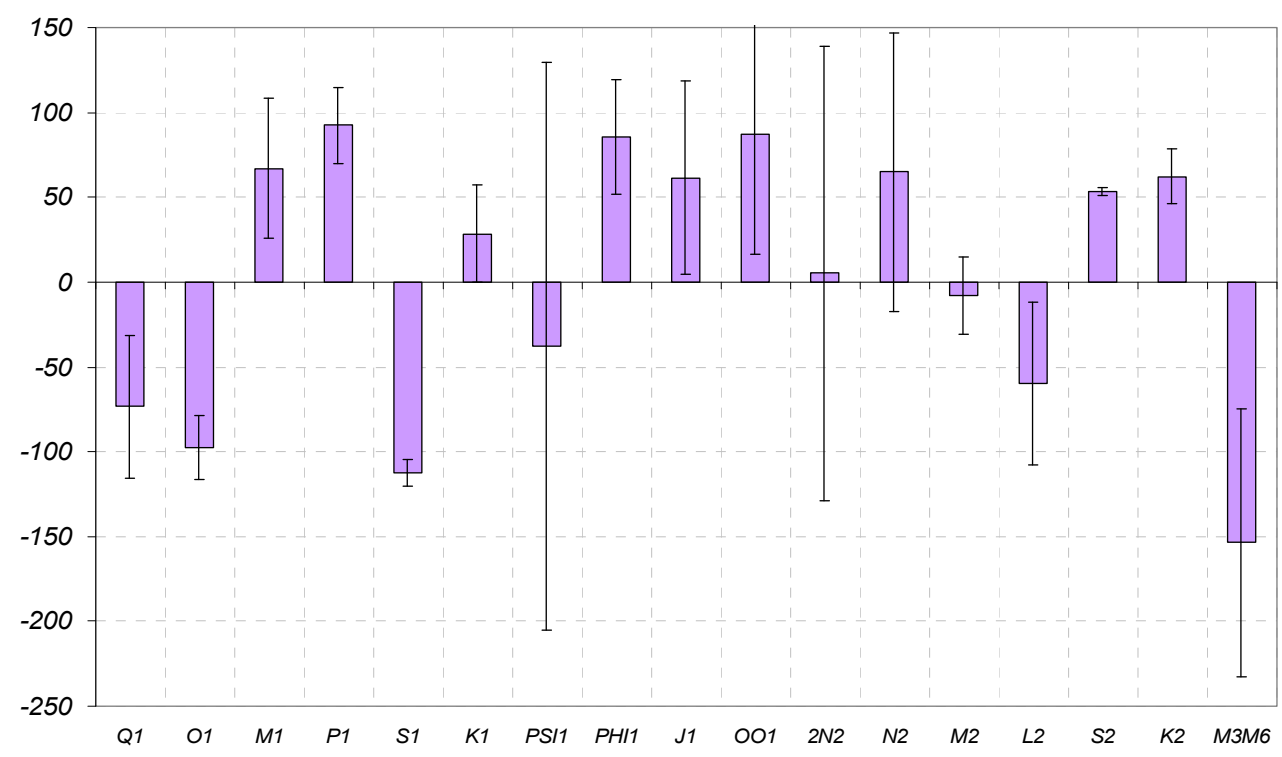

Fig. 13. Phases $\left[{ }^{\circ}\right]$ of the atmospheric gravity effect.

Composition of these values provides us changes of the atmospheric indirect effect in the tidal frequency bands:

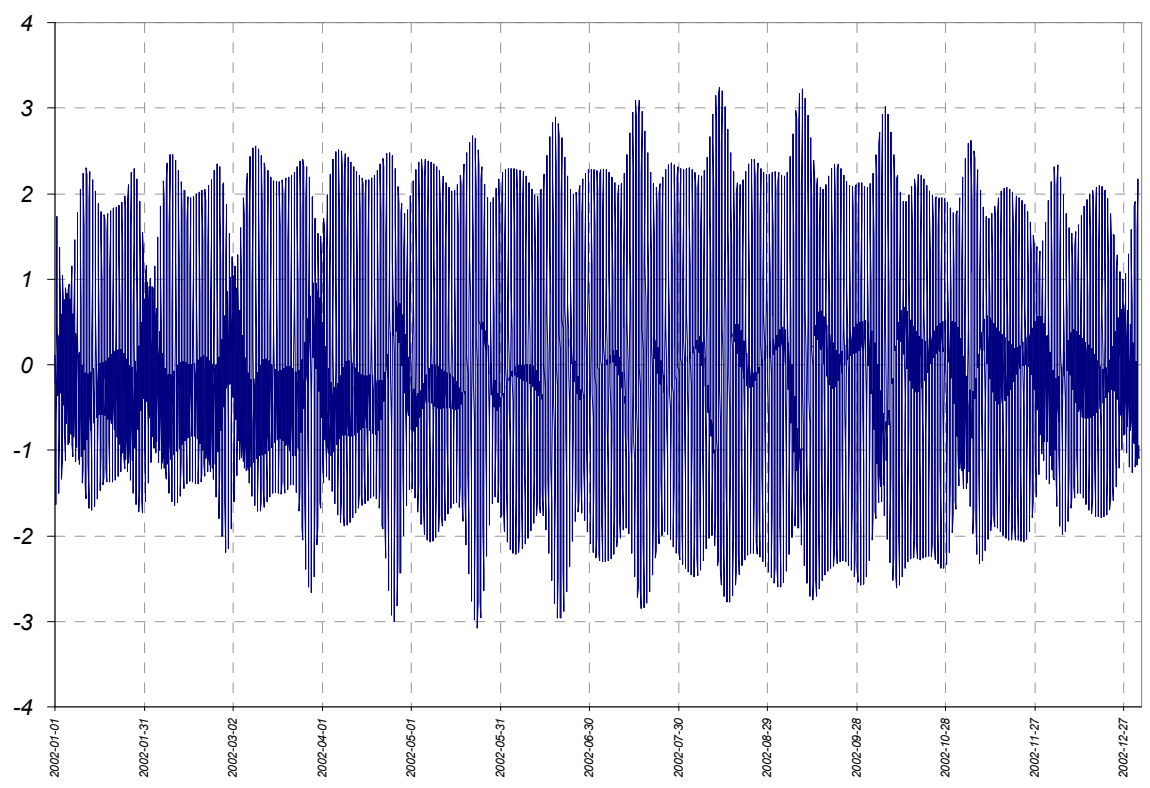

Fig. 14. Atmospheric tidal indirect effect $\left[\mathrm{nm} / \mathrm{s}^{\wedge} 2\right]$. 


\subsection{Hydrological observations}

Hydrological cycle in environment can be described as follows:

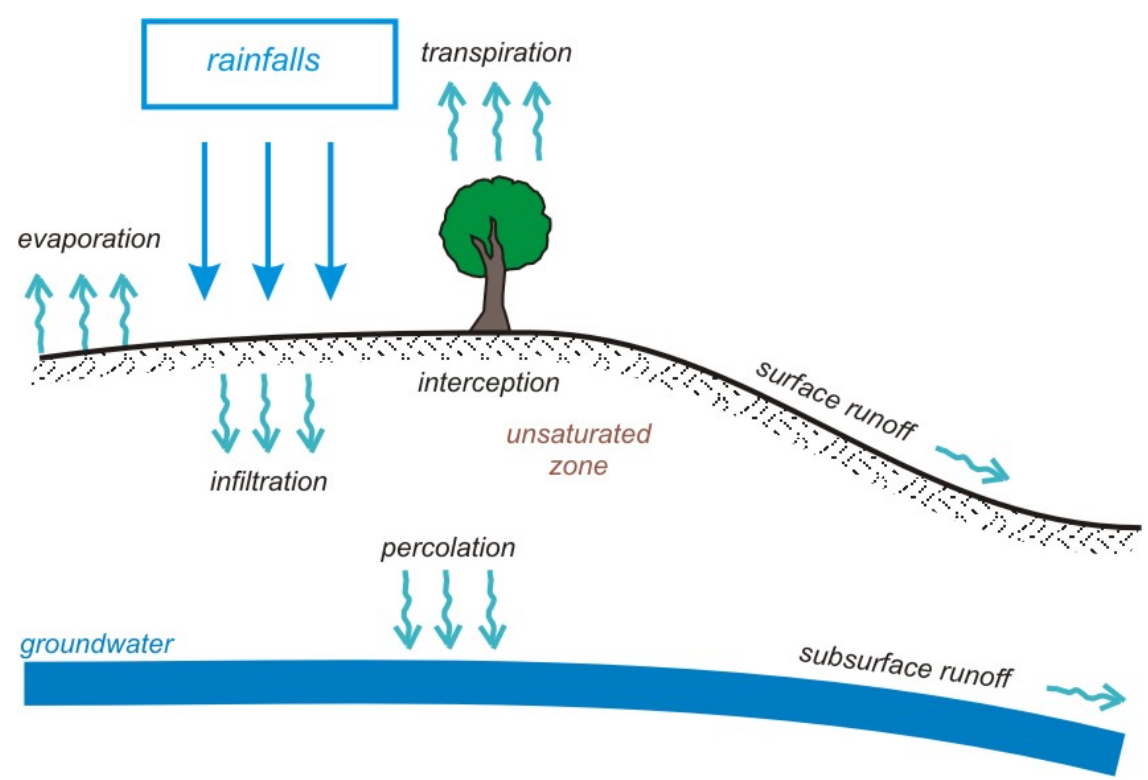

Fig. 15. Hydrological cycle (from Klügel et. al., 2006).

Some of the phenomena pointed out in the sketch should be monitored and concerned in the observations because of their influence on gravity, some of them need to be determined by indirect means. Hence it is not possible to directly observe all components shown at Jozefoslaw Observatory three of them are permanently monitored. These are: ground water table changes, soil moisture and rainfalls.

Determination of the water table level has been made using piezometer which has been placed near the Observatory (fig. 4) since 2002 with one-day sampling rate.

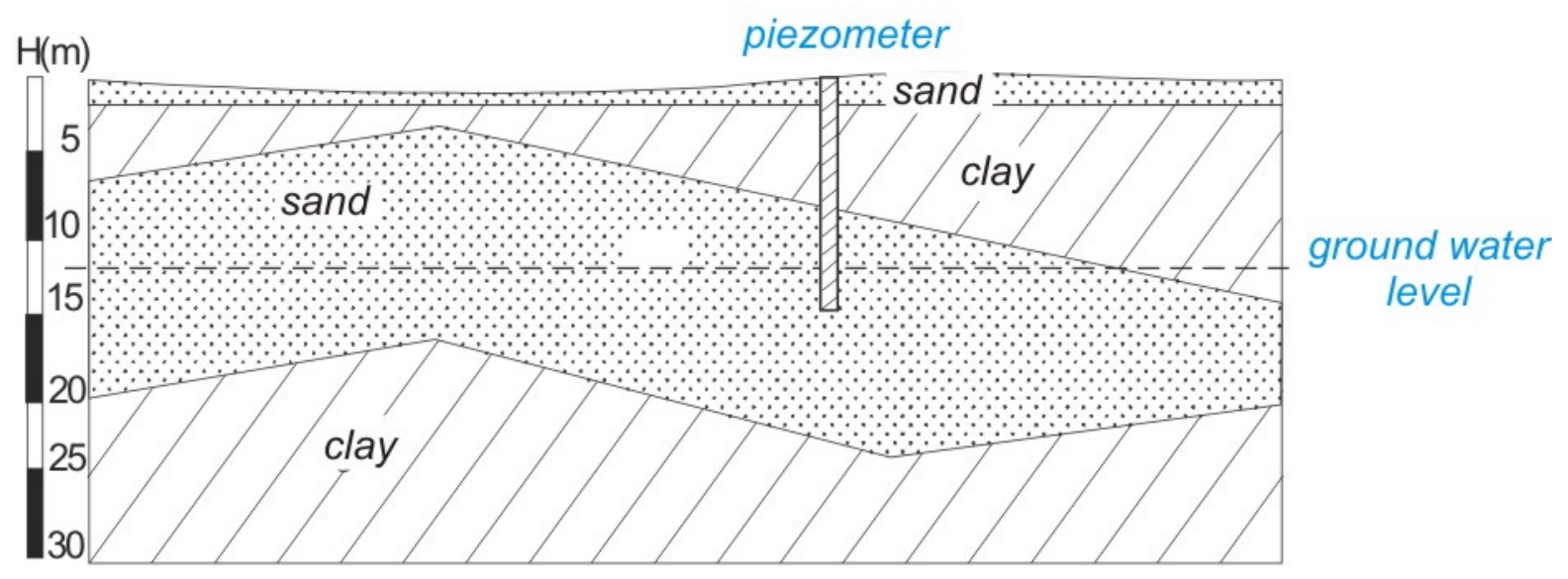

Fig. 16. Geological structure at the vicinity of the Observatory. 


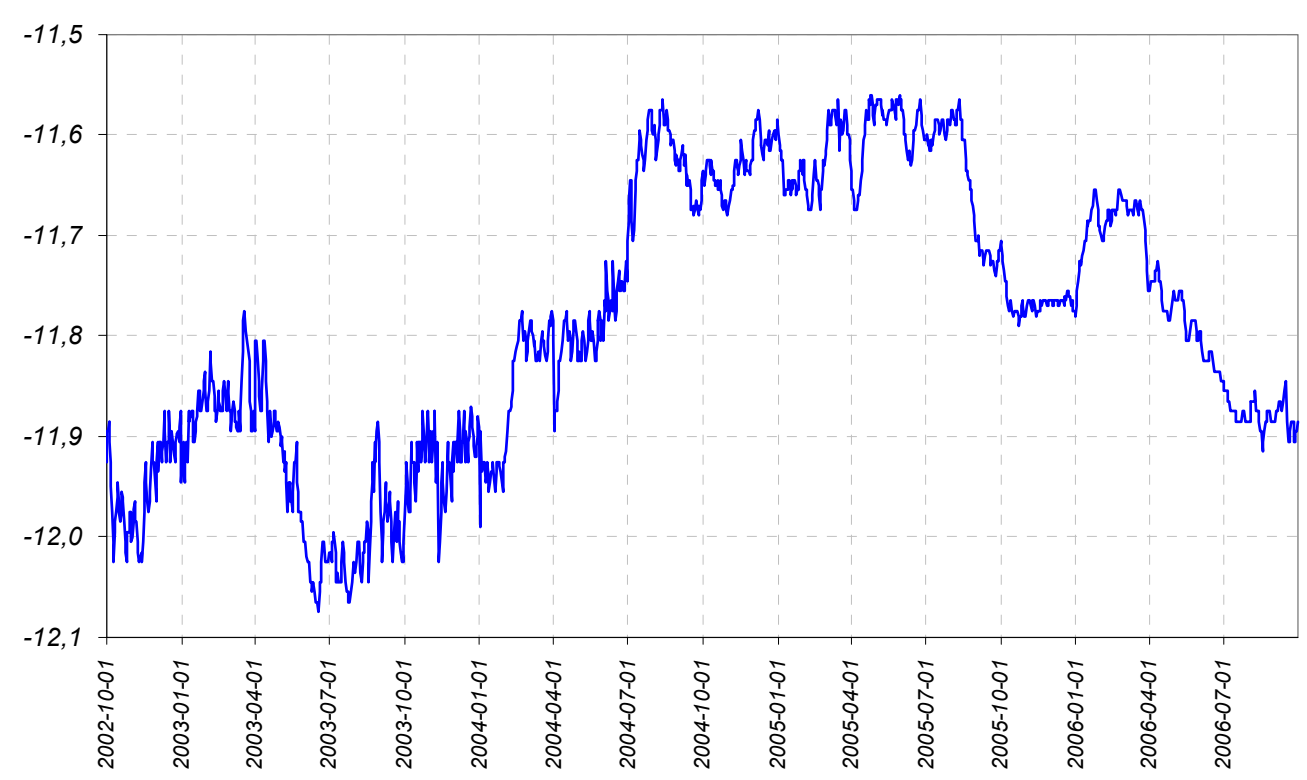

Fig. 17. Changes $[\mathrm{m}]$ of the water level.

Using the formula for Jozefoslaw (Barlik et. al., 1989):

$$
\Delta g\left[\mathrm{~nm} / \mathrm{s}^{2}\right]=102.7 \cdot \Delta H[\mathrm{~m}]
$$

where $\Delta H$ is measured change of water level, changes of the gravity due to water level changes were obtained:

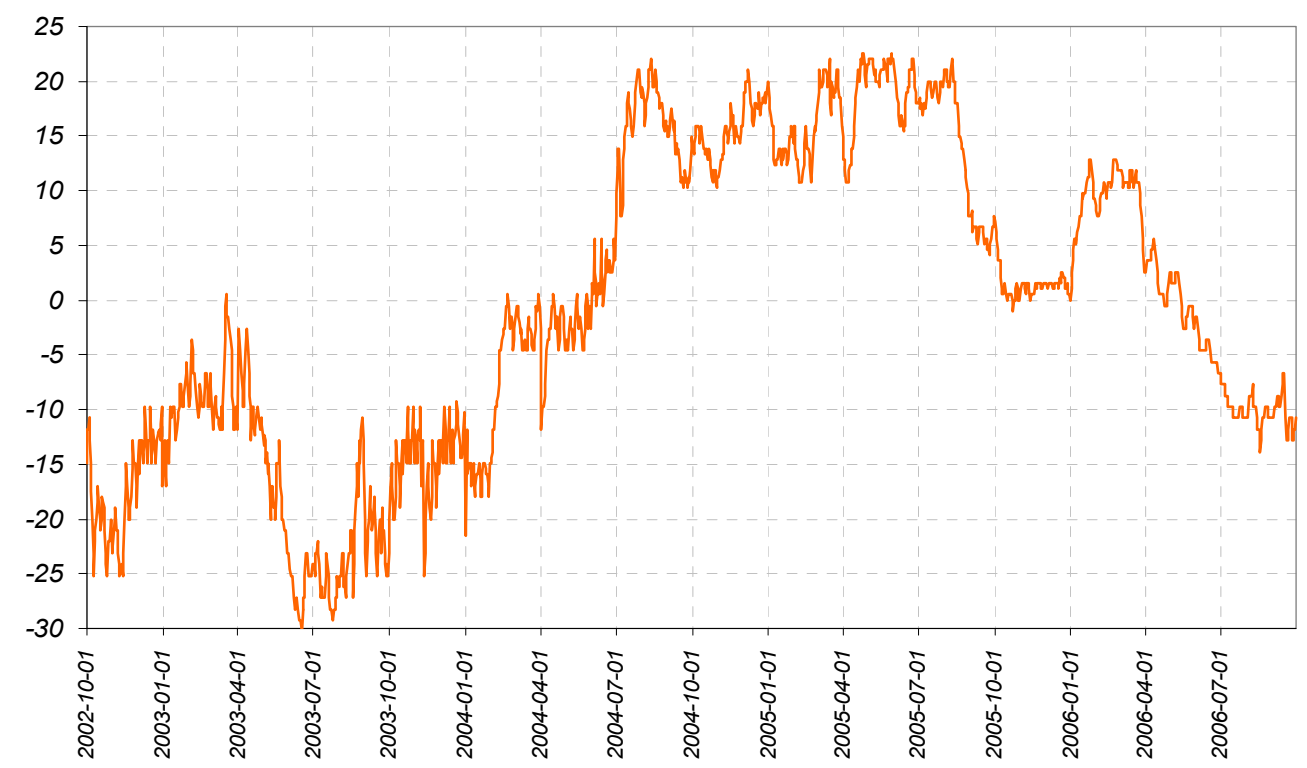

Fig. 18. Changes in gravity $\left[\mathrm{nm} / \mathrm{s}^{\wedge} 2\right]$ due to the water level changes.

Tidal analyses of the observations at a daily interval make no sense (maybe for longperiod tides determination...). The change of the sampling rate from 1-day to 1-hour is necessary. There is no certainty, that piezometer measures the changes of level of underground waters, which existence is confirmed, and not only little underground lake. Checking this would require expensive geological investigations.

To monitor precipitation events a special gauge was installed (fig. 4). The dataset collected during 2005 is presented in fig. 19. 


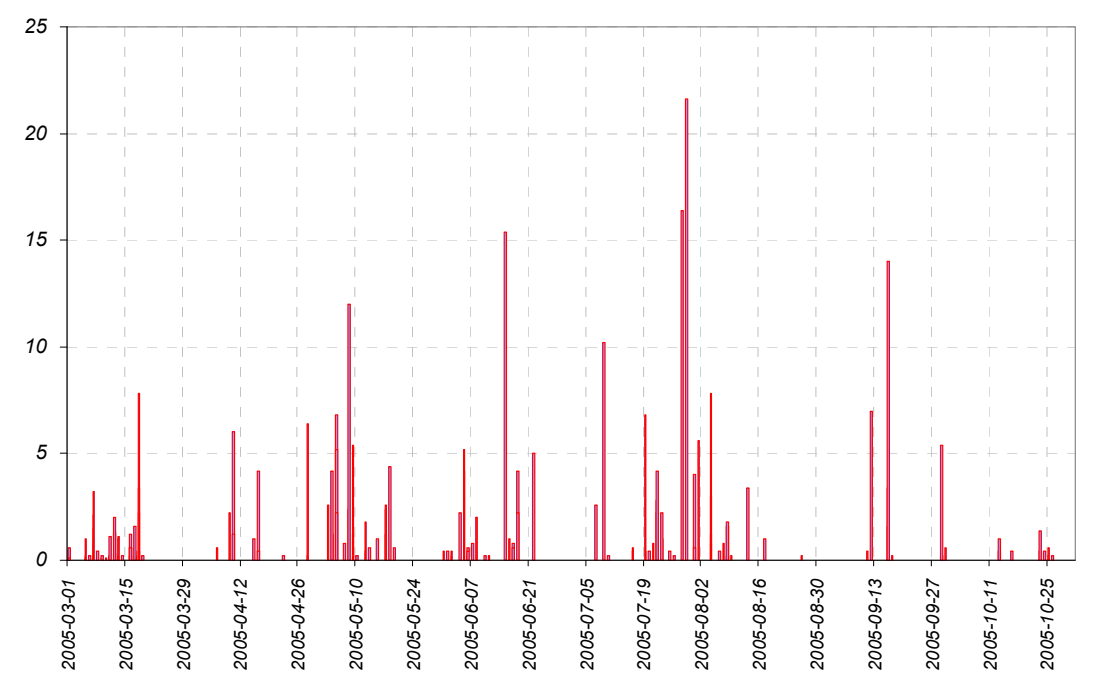

Fig. 19. Rainfalls $[\mathrm{mm} / \mathrm{h}]$ in Jozefoslaw in 2005.

The procedure of the determination of the gravity changes due to the rainfalls is based on two parameters (Crossley and Van Dam, 1997):

$$
\Delta g=2 \pi G \rho r_{j}\left(1-e^{-(i-j) / \tau_{1}}\right) e^{-(i-j) / \tau_{2}}
$$

$\tau_{1}$ describes the infiltration of water into the ground (,,recharge time constant");

$\tau_{2}$ describes the gradual dry out of the ground (,discharge time constant");

$r_{j}$ describes amount of the rainfalls in $i$-th moment of time.

Both time constants depend on many physical, hydrological and biological parameters, which otherwise cannot be included in detail in a model for practical use. Fig. 20 presents changes of the gravity in Jozefoslaw due to the rainfalls. The values of $\tau_{I}=4$ hours and $\tau_{l}=91$ days (adjusted to the SG observations at Boulder) were used in this research.

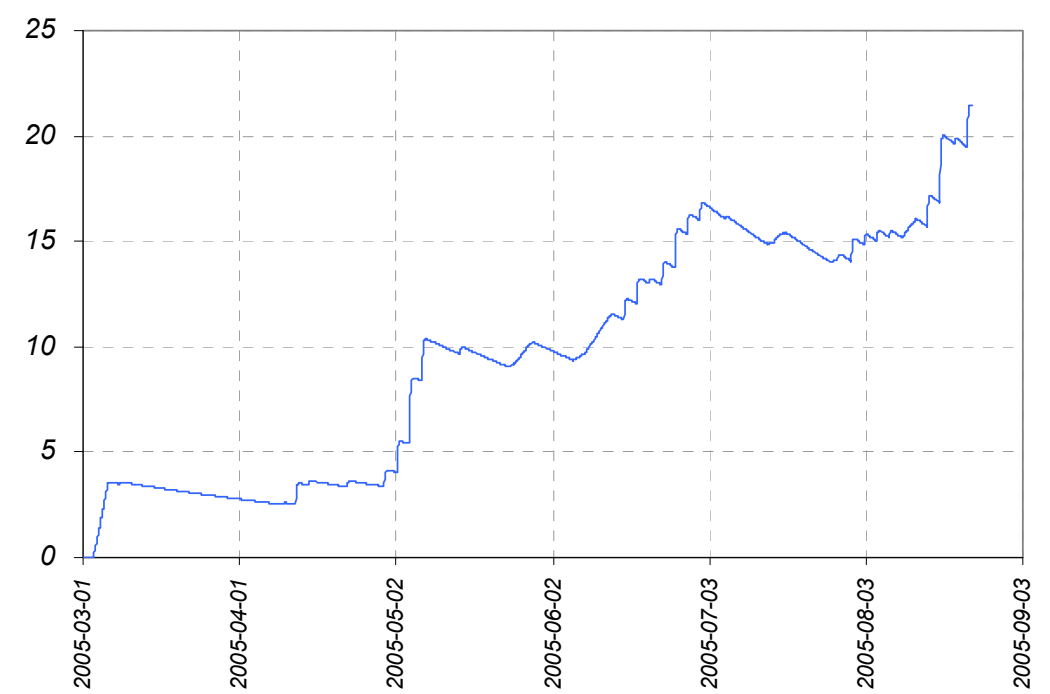

Fig. 20. Changes of the gravity $\left[\mathrm{nm} / \mathrm{s}^{\wedge} 2\right]$ in Jozefoslaw in 2005 due to the rainfalls.

To make the determination of the environmental influence more complete the soil moisture sensors were installed (fig. 4). Geological researches showed differences in the soil structure (clay and sand with clay) near the building that the gravimeter was put. So the decision was taken to establish two sensors. Originally the Eigenbrodt's sensors were put, but 
they were borrowed just for tests. So we have decided to take samples which were taken on alternatively from individual places from $0.5 \mathrm{~m}$ depth. The averaged results are presented below. These changes are rather significant, because of very dry weather in 2006 . The samples were taken twice a week. Blue line indicates data from point number 1 (fig. 4), red from point number 2 .

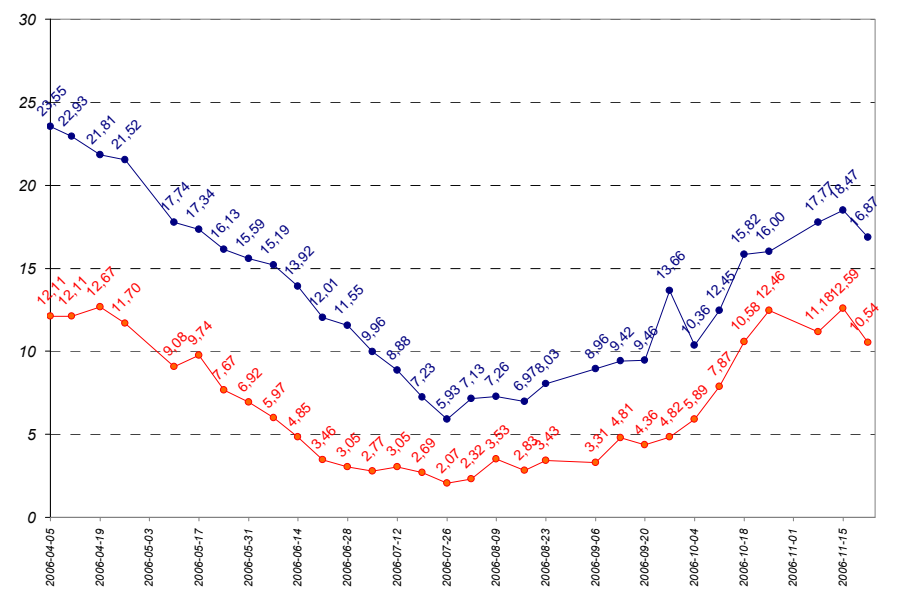

Fig. 21. Averaged changes of the soil moisture [\%] in 2006.

The gravity changes calculated for a Bouguer plate using the method described in details in (Torge, 1989) using the density of about $999 \mathrm{~kg} / \mathrm{m}^{3}$ for water, a thickness of $1 \mathrm{~m}$ :

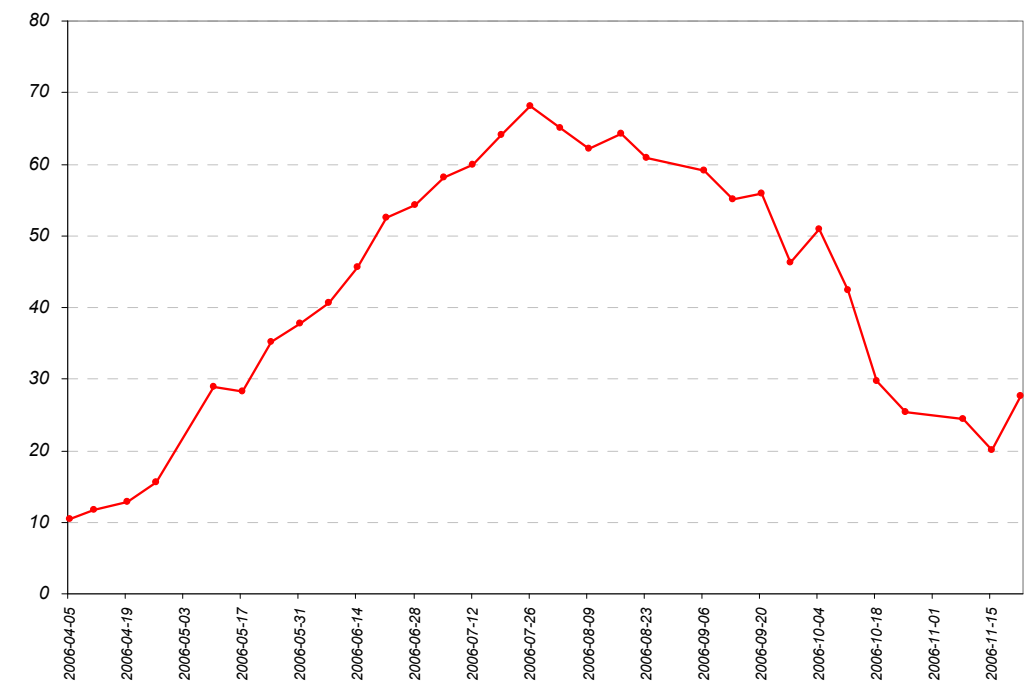

Fig. 22. Gravity changes $\left[\mathrm{nm} / \mathrm{s}^{\wedge} 2\right]$ due to the soil moisture in 2006.

It make sense to reduce these effects from gravity as it leads to a better signal-to-noise ration in the gravity data and thus improves the result of the tidal analysis. 


\section{RESULTS}

Environmental effects have to be very carefully removed from the observations using scheme described in details in (Melchior, 1983):

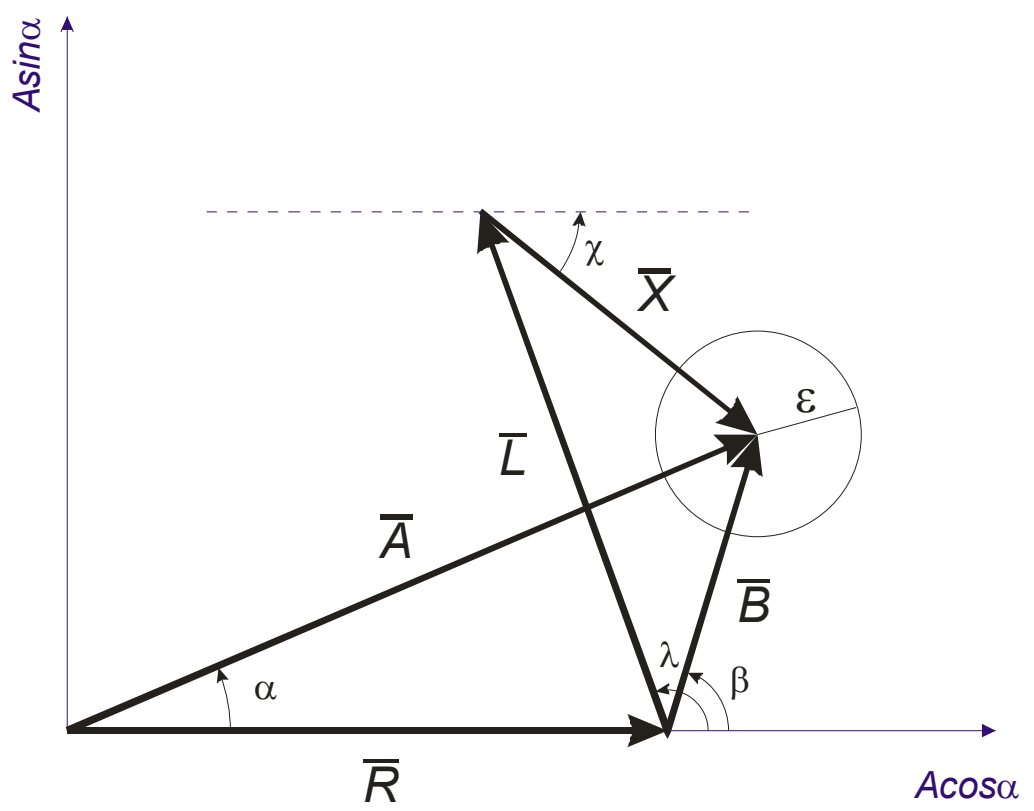

Fig. 23. Method of indirect effects correcting.

In this figure:

$R$ - the theoretical vector referred to the rigid and oceanless Earth model,

$A$ - amplitude vector,

$\alpha$ - its phase,

$L-$ vector of the environmental influences,

$\lambda-$ its phase.

Finally we are able to obtain residual vector $X$ and $\chi$ (phase).

The data (time span of 44 months) was analyzed using ETERNA 3.4 Earth tides processing package (Wenzel, 1996). Software is based on the classical manner which utilizes least squares method (Chojnicki, 1977). Environmental reductions were applied beforehand. No hydrological reductions were applied because of insufficient data sampling rate. 
Table 1. The results of tidal analysis with Eterna 3.4 of 1311 days of hourly data.

Gravimetric Earth Tide Station Jozefoslaw no. 909 Poland.

Institute of Geodesy and Geodetic Astronomy,

Warsaw University of Technology, Poland.

52.0973N 21.0316E H141M Gravity.

Gravimeter LaCoste-Romberg no. ET26 electrostatic feedback.

Digital recording with 1 min. interval.

Supervisor J. Bogusz, IGGA.

206.5 s instrumental time lag corrected during preprocessing.

$\begin{array}{rccccc}\text { from } & \text { to } & \text { wave ampl. } & \text { ampl.fac. stdv. } & \text { ph. lead } & \text { stdv. } \\ \text { cpd] } & {[\mathrm{cpd}]} & {\left[\mathrm{nm} / \mathrm{s}^{* *} 2\right]} & & {[\mathrm{deg}]} & {[\mathrm{deg}]}\end{array}$

\begin{tabular}{|c|c|c|c|c|c|c|c|}
\hline 370 & 7 & SGQ1 & 244 & 876 & 507 & 51 & 528 \\
\hline .842148 & 0.860293 & $2 Q 1$ & 7.6350 & 15713 & 0.03411 & -2.7633 & 1.6886 \\
\hline 0294 & 878674 & SGM1 & 9.2069 & 16867 & 0.02648 & -0.0527 & 1.2986 \\
\hline .878675 & 0.896968 & Q1 & 57.6960 & L. 15013 & 0.00401 & -0.4084 & 0.1999 \\
\hline 96969 & 911390 & R01 & 10.9513 & L. 14514 & 0.02018 & -0.4756 & 1.0098 \\
\hline 391 & 931206 & 01 & 301.3400 & 15140 & 0.00071 & -0.1375 & 356 \\
\hline .931207 & 0.949286 & TAU1 & 3.9278 & L. 20534 & 0.06683 & -2.7087 & 3.1778 \\
\hline .949287 & 0.967660 & M1 & 23.6870 & .15500 & 0.00797 & 0.0436 & 0.3955 \\
\hline 7661 & 31854 & CHI1 & 326 & 1731 & 995 & 0939 & \\
\hline .981855 & 0.996055 & PI1 & 8.1943 & .10690 & 0.03029 & -3.2865 & 1.5677 \\
\hline .996056 & 0.998631 & P1 & 140.1888 & 1.14976 & 0.00179 & 0.0690 & 0.0894 \\
\hline .998632 & 001 & S1 & 37 & 4182 & 37 & -60. & 962 \\
\hline 370 & 1.004107 & K1 & 423.6256 & 13654 & 0.00055 & -0.0465 & 278 \\
\hline 1.004108 & 1.006845 & PSI1 & 3.3153 & 1.45061 & 0.07423 & -3.4797 & 2.9329 \\
\hline .006846 & 1.023622 & PHI1 & 6.0322 & 3 & 0. & -3. & 294 \\
\hline .023623 & 035250 & TET1 & 4.5312 & .19458 & 91 & 1.3389 & 2.3937 \\
\hline L. 035251 & 1.05 & J1 & 955 & 1. & & & 5167 \\
\hline 1.054821 & 1.07 & S01 & 3.9299 & . 21257 & 0.0 & -1. & 994 \\
\hline 1.071834 & 1.090052 & 001 & 12.9608 & .17778 & 0.01360 & 0.0292 & 0.6617 \\
\hline 1.090053 & 1.470243 & NU1 & 2.4820 & 1.11483 & 0.0 & 0. & 3.6953 \\
\hline 14 & 1.84 & EPS2 & 2.0 & & & & 016 \\
\hline 1.845945 & 1.863026 & 2N2 & 7.1896 & .17639 & 0.02640 & 3.4348 & 1.2857 \\
\hline 1.863027 & 1.880264 & MU2 & 8.6772 & 1.16144 & 0.0 & 2.5 & 0.9802 \\
\hline 65 & .897 & N2 & & & & & 888 \\
\hline L. 897352 & 1.915 & NU2 & 204 & 9 & & & 996 \\
\hline L. 915115 & .950493 & M2 & 283.7601 & 1.18054 & 0. & 0.2267 & 0.0285 \\
\hline 1.950 & .970390 & L2 & 8.0213 & 65 & 0.6 & -0. & 0.6201 \\
\hline 391 & 1.998996 & T? & 7.7159 & & & -0. & 507 \\
\hline & & S2 & 132 & 0 & & -0.3138 & 0592 \\
\hline 2.001679 & 2.468043 & at & 35.8682 & 1.18557 & 0.00372 & 0.1369 & 0.1797 \\
\hline .468044 & 7.000000 & M3M6 & 3.4287 & 1.07943 & 0.01069 & -1.4262 & 0.5676 \\
\hline
\end{tabular}

Standard deviation:

Degree of freedom:

Maximum residual:

Maximum correlation:

Condition number of normal equ.

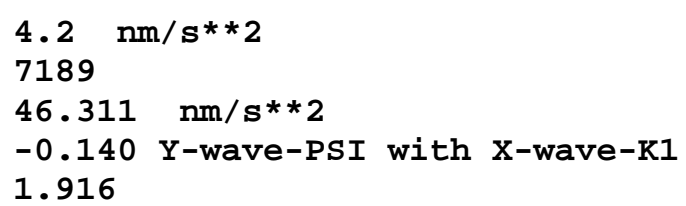

Results in the table 1 are given here for information purposes and to give the idea of quality of measurements. After the adjustment the maximum residuum is about $46 \mathrm{~nm} / \mathrm{s}^{\wedge} 2$ (fig. 24) which is relatively high. There is still no explanation for that but it could be explained by clay on which the pillar is placed. In particular days there is observed strong correlation between rainfalls and enlarged short-term oscillations of the instrument's measuring system. Besides in the next research checking the calibration of the ET gravimeter is intended. It has been already calibrated on the vertical base in Austin, Texas in 2001 before shipping to Poland, but it will be also compared to the absolute gravity measurements which 
are carried out in Jozefoslaw using FG-5 No 231. The mean square error of $4.2 \mathrm{~nm} / \mathrm{s}^{\wedge} 2$ and the drift of $-4.5 \mathrm{~nm} / \mathrm{s}^{\wedge} 2$ per month are acceptable for this type of equipment.

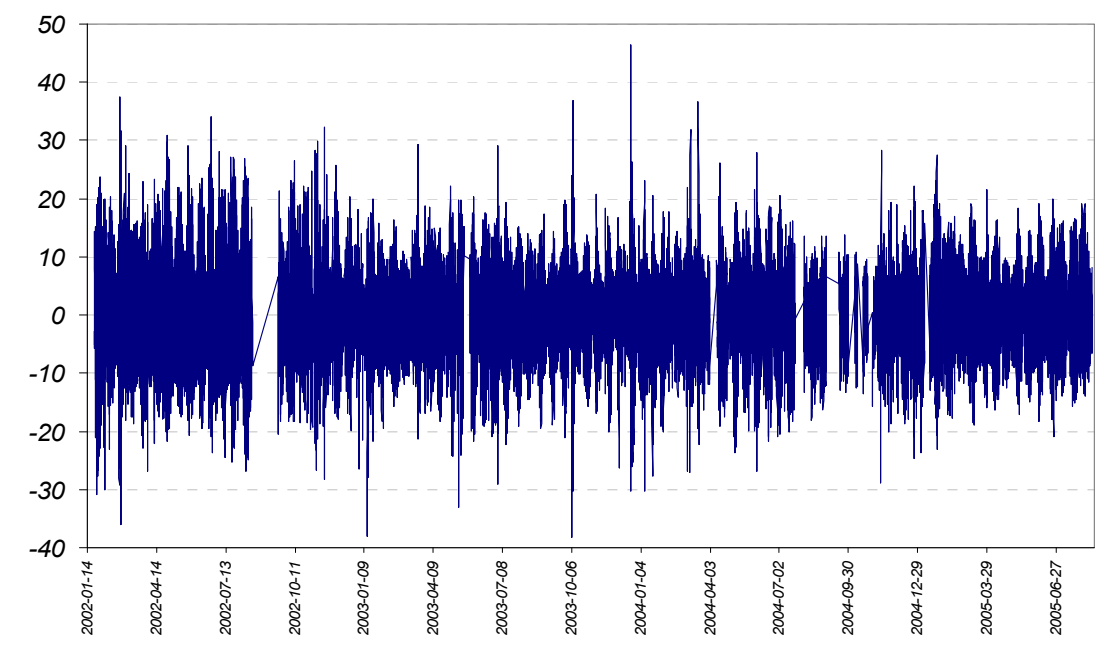

Fig. 24. Gravity residua $\left[\mathrm{nm} / \mathrm{s}^{\wedge} 2\right]$.

Amplitude spectra of gravity residua (fig. 25) still show some oscillations in tidal bands, but their existence could be rather explained by the imperfectness of the method of data adjustment and instrumental or station noise.

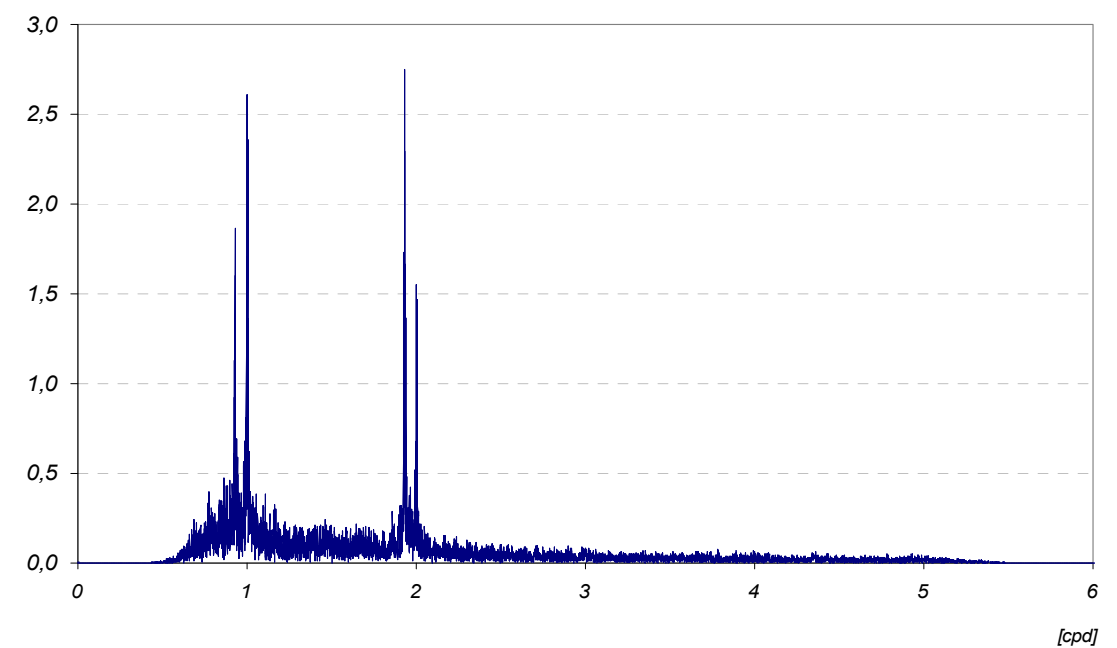

Fig. 25. Amplitude spectrum of gravity residua $\left[\mathrm{nm} / \mathrm{s}^{\wedge} 2\right]$ 


\section{CONCLUSIONS}

The data treatment has not been finished yet and the applied corrections still have to be improved. The presented research showed how the elimination of environmental influences is an important element of tidal observations recorded at Jozefoslaw. The tidal model, which is the result of analysis, should contain all elements connected with environmental effects. But new equipment for hydrological changes monitoring is necessary to be installed in the Observatory. The model determined for Jozefoslaw was sent to International Centre for Earth Tides, where it figures as official one.

It is also worth mentioned that in case of atmospheric tides main influence comes from the solar harmonics and the broadband energy spectrum of air pressure with energy at tidal frequencies. Hydrological variations also present a significant influence on gravity, but the tides seldom could be found in them, nonetheless we need to take care of these effects, because their have a broadband spectrum and thus energy at tidal frequencies.

Acknowledgements. This research was supported by the Polish Ministry of Science, grant no. 4 T12E 00327.

\section{REFERENCES}

Barlik M., Rogowski J. B. (1989): „Variation of the Plumb line Direction Obtained from Astronomical and Gravimetric Observations". Prace Naukowe PW. Geodezja z. 33, pp. 135-168.

Bogusz J. (2000) - "Investigation of Atmospheric Influence to the Gravimetric Tidal Observations". Warsaw University of Technology Printing House 2000. Ph. D. Thesis.

Chojnicki T. (1977): „Sur l'analyse des observations de marees terrestres”. Ann. Geophys., 33, 1/2, Edition du CNRS, Paris, pp. 157-160.

Crossley D., van Dam T. (1997): „Comprehensive Analysis of 2 years of SG Data from Table Mountain, Colorado". Proceedings of the 13th International Symposium of Earth Tides, Brussels, August 22 - September 1st, 1997. Série Géophysique of the Royal Observatory of Belgium : 3, Avenue Circulaire, B-1180, Brussels, Belgium, pp. 659-668.

Farrel, W.E. (1972): Deformation of the Earth by surface loads. Revue of Geophysics and Space Physics, Vol. 10, pp. 761-797.

Klügel T., Harnisch G., Harnisch M. (2006): „Measuring integral soil moisture variations using a geoelectrical resistivity meter". Paper presented at the Workshop on Analysis of Data from Superconducting Gravimeters and Deformation Observations regarding Geodynamic Signals and Environmental Influences Jena, March 27 - 31, 2006. Bulletin d'Information des Marées Terrestres (BIM), No. 141-142, pp. 11369-11375, 15th August 2006.

Melchior P. (1983): “The Tides of the Planet Earth". Pergamon Press.

Ray R. (1999): “A global ocean tide model from Topex/Poseidon altimetry: GOT99.2”. NASA Technical Memorandum 209478, 58 pages, Sept. 1999.

Torge, W. (1989): “Gravimetry”. Walter de Gruyter Verlag, Berlin 1989. 
Van Camp, M., and Vauterin, P. (2005): "Tsoft: graphical and interactive software for the analysis of time series and Earth tides", Computers \& Geosciences, 31(5), pp. 631-640.

Wenzel H.-G. (1996): "The nanogal software: Earth tide processing package ETERNA 3.30". Bulletin d'Information des Marées Terrestres (BIM), No. 124, pp. 9425-9439, Bruxelles, 1996.

Received: 2007-03-26,

Reviewed: 2007-10-25, by C. Kroner,

Accepted: 2007-11-07. 